\title{
The effect of movement on the perceived brightness of chromatic afterimages
}

\author{
JOHN G. SEAMON AND LEON W. TEFT, UNIVERSITY OF \\ BRIDGEPORT, Bridgeport. Connecticut
}

The present stady explored the effects of adaplation to static and moving chromatic stimuli on the perceived brightness of afterimages projected on static and moning achromatic test stimuli. The Ss were presented with two stimuli of the same color to which they adapted for I min. The Ss then reported the brightness of their afterimages when viewing achronnatic stimuli. A rotating stimulus, viz, 16,45 , or $7 \mathrm{~s}^{\prime} \mathrm{mm}$. was compared with a stationary stimulus. Results indicate that $(a)$ the introduction of movement detracts fiom the brighthess of an afterimage, and $(b)$ a speed of 45 rmm affects the afterimage more than 16 or $7.5 \mathrm{rmm}$.

Speed of stimulus rotation has been shown to have a direct relationship to duration and strength of movement aftereffects (Granit, 1927; Thomas, 1963). Research on the problem of the effect of movement on chromatic afterimages has received little experimental attention. Wheeler \& LaForce (1967) studied the effects of disc rotation speed, chromaticity and luminosity of a color pulse with a Bilwell-type apparatus. In an analysis of their data a comparison of low rotation speeds $(10-60 \mathrm{cps})$ with high rotation speeds $(60-110 \mathrm{cps})$ indicates that the low speeds produced brighter negative afterimages in $46.7 \%$ of the trials, while the high speeds yielded brighter afterimages in only $6.7 \%$ of the trials. The percentages indicate that speed of movement may have an inverse relationship to the perceived brightness of chromatic afterimages. The present experiment sought to continue research in this area by exploring the effect of static and slow moving stimuli on the brightness of afterimages.

Method. Three students, each with at least $3 \mathrm{~h}$ of previous experience with color afterimages, served as Ss.

Two 12 in. diameter, white cardboard discs, both bisected by a $1 / 4$ in. $x 12$ in. black line, were used as stimuli. Each stimulus was mounted on a three speed turntable which permitted clockwise rotations of 16,45 , and $78 \mathrm{rpn}$. The turntables were placed side by side below the $S$ 's line of sight. The rear of each turntable was elevated to permit the $S$ to view each disc fully while seated at a distance of $4 \mathrm{ft}$. The stimuli were viewed through a pair of $11 / 2 \mathrm{in}$. $x 7 \frac{1}{2}$ in. tubes which prevented the two monocular fields from overlapping and ruled out extraneous light stimulation. Coloration of the discs was provided by red or green acetate filters placed over the stimuli.

To test the effect of movement on afterimages a stationary stimulus was compared with a rotating stimulus. Each disc had a filter of the same color, e.g., red or green. The procedure consisted of $S$ adapting to the two stimuli for $1 \mathrm{~min}$. The $\mathbf{S}$ was instructed to use the spindle of each turntable as the center of each visual field to insure that each eye received equal stimulation. In this manner the two fields did not overlap, but seemed to touch on their

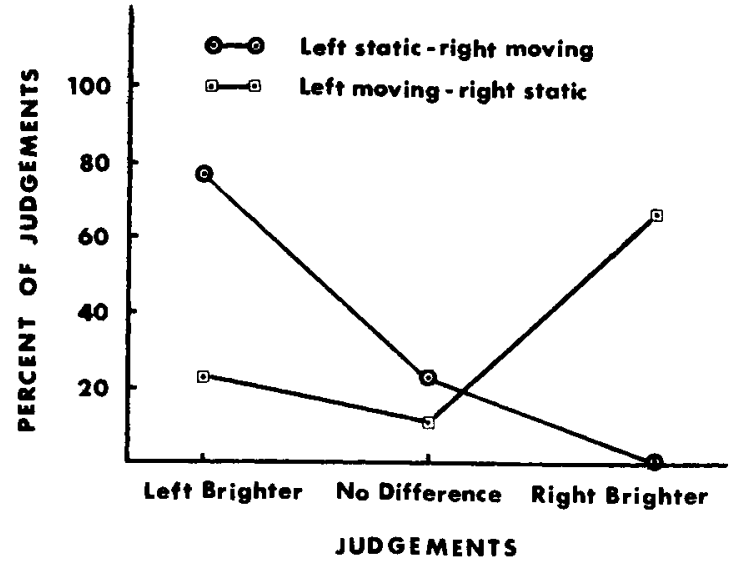

Fig. 1. Perceived brightness of afterimages with static and moving test stimuli following static adaptation.

Psychon. Sci., 1968, Vol. 11 (2) inner edge. The $S$ was instructed to lixalc at this point. following adaptation $S$ was asked to close his eyes while te removed the filters from the white dises. The $S$ was then totd to open his eyes and report both his afterimages and any apparent differences in brightness.

tach $S$ reported his afterinages under live stimulus conditions. The first two conditions, serving as controls. consisted of static adaptation and static test stinsuli with red or geen lifters. Condition 3 consisted of static adaptation (red or green) and movement $(16,45$, and $78 \mathrm{rpm})$ in the leti or right test stimulas. Condition 4 involved movement in the left or right stimulus during both adaptation and test. Conditien 5 comsisted of movement in the teft or right stimulus during adaptation and a static test. It should be noted that the $S$ did net undergo two suecessive conditions with the same color. Colors were alternated to pernit each adaptation period to washertit the effects of the previous condition.

Results. All Ss responded with no difference between the afterimages in Conditions 1 and 2 demonstrating that hoth fields were equally effective in producing afterimages. Percived differences in brightness were reported for conditions 3, 4, and 5 . However. only in Condition 3 (static adaptation and movement in one test stimulus) do Ss' reports systematically demonstrate the effect of movement on the perceived brightness of afterimages. These results are presented in Fig. 1. The curves indicate that the introduction of movement in one test stimulus detracted from or inhibited the brightness of the afterimage. The results from conditions 4 and 5 do not demonstrate any systematic tendency for Ss to report one test stimulus as being brighter than the other.

The $\mathrm{Ss}^{\circ}$ responses were also examined as a function of threc speeds of stimulus novement. The datit from combined Conditions 3,4 , and 5 for stimuli at 45 rpm are presented in Fig. 2 . These data, analyzed in terms of differences between perceived brightness for static stimulus left and right, yiclded curves of greatest difference, viz, maximal inhibition of the afterimage. The data for 16 and 78 rpm show the same trend. but not of comparable magnitude.

Discussion. In review, the present study indicates that (a) the introduction of movement detracts from the perceived brightness of a chromatic afterimage, and (b) a speed of $45 \mathrm{rpm}$ inhibits the brightness of an afterimage more than 16 or $78 \mathrm{rpm}$. The first finding is consistent with Wheeler \& LaForce's (1967) observation of an inverse relationship between specd of rotation and brightness of afterimage. The second finding. however. is it apparent disagreement. In the present study an angular rotation of $78 \mathrm{rpm}$ resulted in a brighter afterimage than obtained with $45 \mathrm{rpm}$. A possible explanation for the disparity in the findings of the two studies may be found in Wheeler \& LaForce's grouping of all speeds into two categories, low and high speeds, in which small variations may have been averaged out. Further research on the brightness of afterimages generated by a wide range of stimulus speeds should resolve this question.

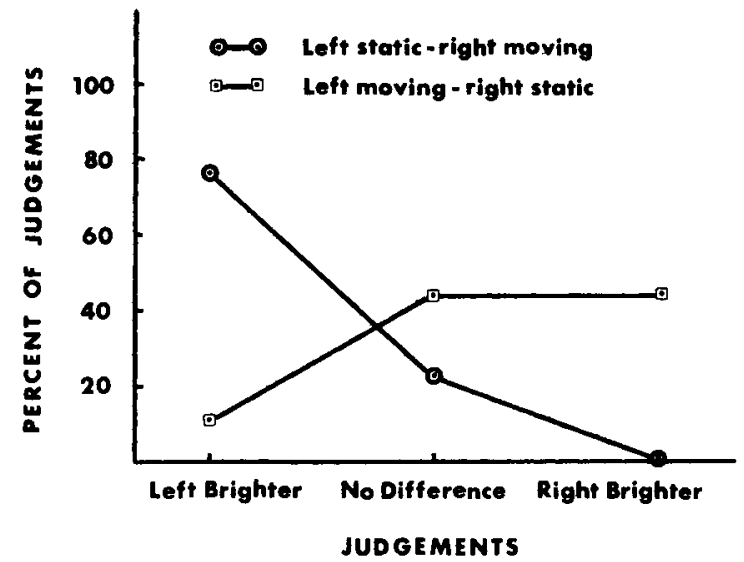

Fig. 2. Perceived brightness of afterimages for Conditions 3,4 , and 5 with a stimulus speed of $45 \mathrm{rpm}$.

\footnotetext{
Psychon. Sci., 1968, Vol. 11 (2)
} 


\section{REFERENCES}

GRANIT, R. Über eine Hemmung der Zapfenfunktion durch Stäbchenerregung beim Bewegungsnachbild. (Concerning an inhibition of the function of the cones through the excitation of the rods in afterimages of movement.) Zeitschrift fur Sinnesphysiologie, 1927, 58, 95-110.
THOMAS, P. L. A study of the relation of stimulus design and rotation speed to the spiral aftereffect. Dissert. Abstr., 1963, 24, 1715-1716.

WHEELER, L., \& LaFORCE, R. C. Sustained Bidwell afterimages: Effects of disc rotation speed, color-pulse chromaticity, and color-pulse luminance. $J$. Opt. Soc. Amer., 1967, 57, 386-393. 